\title{
Новые материалы для гетеро- и фотокатализа на основе синтетических титаносиликатных аналогов минералов Хибин
}

\author{
Калашникова Г.О. ${ }^{1}$, Тимофеева М.Н. ${ }^{2}$, Селиванова Е.А. ${ }^{1}$, Самбуров Г.О. ${ }^{1}$, Киселев Ю.Г. ${ }^{1}$, \\ Щукина Е.С. ${ }^{1}$, Пахомовский Я.А. ${ }^{1}$ \\ ${ }^{I}$ ФИЦ КНЦ РАН, Anamumbl, g.kalashnikova@ksc.ru \\ ${ }^{2}$ Институт катализа им Г.К. Борескова СО РАН, Новосибирск, timofeeva@catalysis.ru
}

Аннотация. Рассмотрена перспектива применения синтетических титаносиликатов в качестве материала для областей фото- и гетерокатализа. Изучена фотокаталитическая активность аналогов минералов линтисита, иванюкита, зорита, коробицынита, ситинакита по отношению к раствору ферроина в видимой части света при $\lambda=546$ нм. Определено, что наибольшей степенью разрушения органического индикатора обладает смесь IONSIVE-IE+ETS-4+SIV (68.72 \%), а также синтетический аналог иванюкита SIV (42.63 \%) и коробицынита SKR (31.48 \%). Показано, что на основе титаносиликата AM-4 можно получить перспективный, редкий, осно́вный гетерогенный катализатор для органического синтеза при его обработке раствором кислоты и перехода кристаллической структуры в соединение SL3.

Ключевые слова: титаносиликат, синтетический аналог, минерал, AM-4, SIV, ETS-4, SKR, IONSIVE-IE, анатаз, катализатор, фотокатализ, гетерогенный катализ.

\section{New materials for heterogeneous catalysis and photocatalysis based on synthetic titanosilicate analogues of the Khibiny Mountain minerals}

\author{
Kalashnikova G.O. ${ }^{1}$, Timofeeva M.N. ${ }^{2}$, Selivanova E.A. ${ }^{1}$, Samburov G.O. ${ }^{1}$, Kiselev Yu. G. ${ }^{1}$, \\ Shchukina E.S. ${ }^{1}$, Pakhomovsky Ya.A. ${ }^{1}$ \\ ${ }^{1}$ Kola Science Centre RAS, Apatity, g.kalashnikova@ksc.ru \\ ${ }^{2}$ Boreskov Institute of Catalysis SB RAS, Novosibirsk, timofeeva@catalysis.ru
}

\begin{abstract}
The prospect of using synthetic titanosilicate as a material for the area of photo and heterogeneous catalysis was indicated. Photocatalytic activity of analogues of natural minerals lintisite, ivanyukite, zorite, korobitsynite, sitinakite was investigated towards the solution of ferroin in the visible part of light with $\lambda=546 \mathrm{~nm}$. It was determined that the highest degree of destruction of the organic indicator had a mixture of IONSIVE-IE, ETS-4 and SIV (68.72\%), as well as a synthetic analogues of ivanyukite SIV (42.63\%) and korobitsynite SKR (31.48 \%). It was shown that it is possible to obtain a promising, rare, heterogeneous catalyst for organic synthesis on the basis of titanosilicate AM-4 after its treatment by an acid solution and the transformation of the AM- 4 crystal structure to the SL3 compound.
\end{abstract}

Key words: titanosilicate, synthetic analog, mineral, AM-4, SIV, ETS-4, SKR, IONSIVE-IE, anatase, catalyst, photocatalysis, heterogeneous catalysis.

\section{Введение}

В природе существуют десятки титаносиликатов - соединений титана и кремния - c разнообразными нанопористыми структурами и уникальными химическими и физическими свойствами. Такие титаносиликатные минералы как зорит, натисит, иванюкит, линтисит и многие другие чрезвычайно редки и встречаются, как правило, в природе только в виде микроскопических количествах. Однако уникальные свойства этих минералов могут быть воспроизведены в их искусственных копиях - аналогах. Над способами их получения из нестандартных для химической лаборатории исходных компонентов много лет трудятся сотрудники Кольского научного центра РАН (Николаев и др., 2017). Для синтеза аналогов перечисленных минералов в КНЦ РАН используют вторичные технические продукты на основе титансодержащего концентрата.

Синтетические титаносиликаты уже широко используются в промышленности как молекулярные сита для разделения газов и очистки растворов от вредных для экологии примесей. Двумя наиболее яркими примерами таких материалов, которые уверенно заняли свое место на миро- 
вом рынке, являются: ETS-4 (синтетический аналог зорита) (Kuznicki, 1989) и сорбенты промышленной линейки IONSIVE-IE (синтетический аналог ситинакита) копании UOP LLC, A Honeywell Company, применяемые главным образом для сорбции из жидких радиоактивных отходов изотопов цезия и стронция. Так, IONSIVE-IE был протестирован компанией UOP на примере отходов, накапливаемых в ядерном могильнике «Саванна-Ривер» (США) (UOP LLC, 2020), и местах крупных аварий: АЭС Фукусима Дайичи (Япония) (IAEA Library, 2015), АЭС Три-Майл-Айленд (США) (UOP LLC, 2020).

Кроме сорбционных свойств особого внимания заслуживают каталитические свойства цеолитоподобных материалов, включая фотокатализ. Фотокаталитические процессы в последние годы находят все более широкое промышленное применение для разложения вредных органических соединений, преобразования солнечной энергии в химическую и электрическую, создания сенсоров и устройств нанофотоники, ускорения процессов органического синтеза и других целей. При этом, наиболее распространённым гетерогенным фотокатализатором является анатаз, что связано с его высокой фотокаталитической активностью, высокой химической стабильностью, низкой стоимостью и отсутствием токсичности (Rempel et al., 2015). Однако фотокатализ с использованием анатаза имеет ряд существенных недостатков. Так, ширина запрещенной зоны в анатазе составляет 3.0-3.2 эВ, а поглощение света лежит в УФ-области спектра, поэтому эффективность работы фотокатализаторов на его основе характеризуется малой чувствительностью к видимому свету и составляет менее $10 \%$. Также наблюдается недостаточно высокий квантовый выход фотопревращения, неудовлетворительная скорость фотокаталитических реакций (Воронова, 2009), низкая удельная поверхность, а также малая адсорбционная способность $\mathrm{TiO}_{2}$. Ввиду данных причин поиск новых перспективных соединений, способных работать в видимой области света является актуальной задачей современного материаловедения.

\section{Исследование фотокаталитических свойств титаносиликатов}

Поскольку большинство исследований посвящено изучению фотокаталитических процессов с участием коммерческого катализатора $\mathrm{TiO}_{2}$ Degussa P25 (Германия), активность которого часто принимается за эталонную, было решено провести поисковые исследования свойств синтезированных авторами титаносиликатов и установить их пригодность для целей фотокаталитической химии в сравнении с Degussa P25.

Для исследования были выбраны и синтезированы следующие титаносиликты: AM-4 (аналог линтисита), SL3 (синтетический аналог декатионизированной формы линтисита), SL3:Ag, SL3:Cs, ETS-4 (аналог зорита), SKR (синтетический аналог коробицынита), IONSIVE-IE (аналог ситинакита) с примесью SIV (аналога иванюкита), SIV, рутил с небольшой примесью ETS-4 и TiO, марки Degussa P25 (70-85 \% анатаза и 15-30 \% рутила). Эксперименты по фотокаталитической активности проводились по описанной в работе (Седнева и др., 2007) методике обесцвечивания ферроина, хорошо зарекомендовавшей себя при оценке фотокаталитических свойств $\mathrm{TiO}_{2}$ и ETS-10. Фотокаталитическую активность (ФКА) указанных титаносиликатов определяли в видимой части света при $\lambda=546$ нм с использованием ярко-красного раствора ферроина. Для этого суспензию, содержащую 0.01 или 0.2 г испытуемого вещества и 15 мл ферроина с концентрацией о-фенантролина 190 мг/л, выдерживали во встряхиваемых стеклянных пробирках при дневном освещении в течение 3 часов. После чего осадок удаляли центрифугированием и трёхкратно измеряли в центрифугатах остаточную концентрацию о-фенантролина (интенсивность окраски) спектрофотометрически по интенсивности максимума поглощения при $\lambda=546$ нм. Эффективность разрушения индикатора $E(\%)$, как меру ФКА, рассчитывали по уравнению:

$$
E=\left[\left(C_{0}-C\right) / \mathrm{C}_{0}\right] \cdot 100 \%,
$$

где $C_{0}$ и $C$ - начальное и остаточное содержание о-фенантролина в растворе.

Эксперименты показали (табл. 1), что наибольшей фотокаталитической активностью обладает смесь IONSIVE-IE, ETS-4 и SIV, а также монофазные SIV, AM-4 и ETS-4. Активность остальных образцов подобна активности образца сравнения - анатазу фирмы «Degussa». По предварительным предположениям этот результат, в первую очередь, обусловлен микропористым строением кристаллической структуры титаносиликатов по сравнению с компактной структурой $\mathrm{TiO}_{2}$ (рис. 1), а также более 
развитой поверхностью их агрегатов. Так удельная площадь поверхности анатаза $-55 \mathrm{~m}^{2} / \Gamma$ (Воронова, 2009), SL3 - $48.22 \mathrm{~m}^{2} / \Gamma ;$ AM-4 - $57.93 \mathrm{~m}^{2} / \Gamma$; SIV- $156.92 \mathrm{~m}^{2} / \Gamma$.

Таблица 1. Эффективность разрушения ферроина (Е, \%) титаносиликатами, $\mathrm{TiO}_{2}$ и образцом сравнения Degussa P25.

Table 1. Efficiency of ferroin destruction $(E, \%)$ with titanosilicates, $\mathrm{TiO}_{2}$ and comparison sample Degussa P25.

\begin{tabular}{|c|c|c|}
\hline Образец & Навеска, 2 & $E, \%$ \\
\hline \multirow{2}{*}{ Degussa P25 } & 0.01 & 5.79 \\
\cline { 2 - 3 } & 0.2 & 4.74 \\
\hline \multirow{2}{*}{ TiO $_{2}$ (рутил) } & 0.01 & 6.32 \\
\cline { 2 - 3 } & 0.2 & 5.79 \\
\hline \multirow{2}{*}{ ETS-4 } & 0.01 & 8.95 \\
\cline { 2 - 3 } & 0.2 & 18.95 \\
\hline AM-4 & 0.01 & 12.11 \\
\hline SKR & 0.2 & 31.48 \\
\hline \multirow{2}{*}{ IONSIVE+ETS-4+SIV } & 0.01 & 15.79 \\
\cline { 2 - 3 } & 0.2 & 68.72 \\
\hline \multirow{2}{*}{ SIV } & 0.01 & 11.05 \\
\cline { 2 - 3 } & 0.2 & 42.63 \\
\hline SL3 & 0.01 & 5.26 \\
\hline SL3:Ag & 0.01 & 5.26 \\
\hline SL3:CsNa & 0.01 & 5.79 \\
\hline
\end{tabular}

\section{Титаносиликат АМ-4 для гетерогенного катализа}

Не проявивший хороших показателей по фотокаталитической активности титаносиликат AM-4 и его протонированная форма SL3, при продолжении исследований их свойств совместно с институтом катализа им. Г.К. Борескова СО РАН, оказался интересным гетерогенным катализатором для реакций синтеза 1.5-бензодиазепина, который используется для производства противосудорожных, анальгетических, седативных, антидепрессивных и снотворных средств (Курченко и др., 2018), а также синтеза 1-метанола-2-пропанола из окиси пропилена и метанола (производство моющих систем, растворителей лаков и красок, гидравлических жидкостей) (Timofeeva et al., 2020).

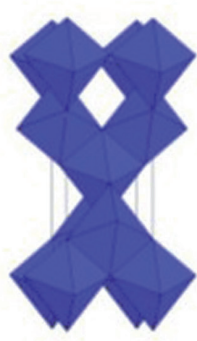

Анатаз

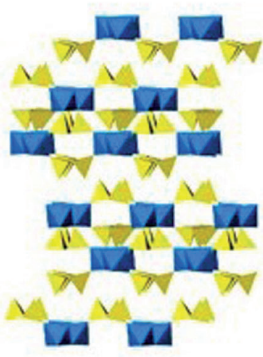

протонированный линтисит(SL3)

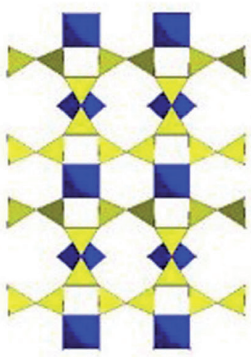

зорит (ETS-4)

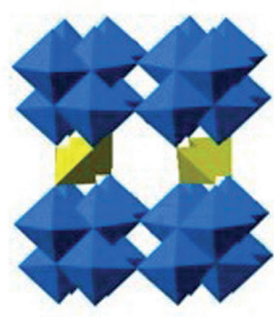

ситннакит (IONSIVE-IE)

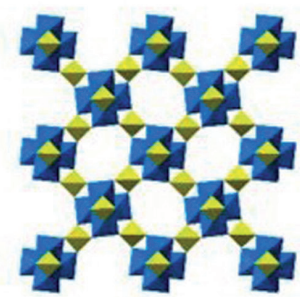

иванюкит (SIV)

Фотоактивность

Рис. 1. Схема зависимости фотоактивности от пористости кристаллического каркаса. Синие октаэдры - $\mathrm{TiO}_{6}$, жёлтые тетраэдры - $\mathrm{SiO}_{4}$.

Fig.1. The dependence of photoactivity on the porosity of the crystal framework. Blue octahedra $-\mathrm{TiO}_{6}$, yellow tetrahedra $-\mathrm{SiO}_{4}$. 
В качестве гетерогенных катализаторов в органическом синтезе в настоящее время в основном применяются материалы с цеолитоподобной структурой (Timofeeva et al., 2017) и глины (González et al., 2017). Осно́вные твердые катализаторы достаточно редки, и для исследователей важно расширить ряд простых в использовании и доступных для промышленности вариантов. Исследовательская работа, проведенная совместно с институтом катализа, показала, что для данных целей потенциал применения AM-4 в качестве катализатора может быть расширен за счет его «кислотной»модификации SL3.

Кристаллическая структура AM-4 состоит из двумерных титаносиликатных наноблоков $\mathrm{Ti}_{2} \mathrm{Si}_{4} \mathrm{O}_{10}(\mathrm{OH})_{4}$, объединенных в единый каркас сшивающими катионами натрия, с образованием широких каналов, занятых внекаркасными катионами натрия и молекулами воды. Кислотная активация данного материала приводит к изменению природы активных центров, что позволяет управлять его каталитическими свойствами. Обработка АM-4 азотной кислотой разной концентрации изменяет свойства его активных центров на более осно́вные, и одновременно повышает поверхностную кислотность материала (табл. 2).

Модифицирование АM-4 проводили азотной кислотой с концентрацией $0.0625,0.125$ и 0.25 моль/л в течение 30 мин при комнатной температуре. Результаты обработки представлены в таблице 2.

Таблица 2. Зависимость свойств поверхности и силы основных центров от кислотной обработки АМ-4.

Table 2. Surface properties of the initial and modified with $\mathrm{HNO}_{3} \mathrm{AM}-4$.

\begin{tabular}{|c|c|c|c|c|}
\hline Образец & $\begin{array}{c}\mathrm{Na} / \mathrm{Si} \\
\text { (моль/моль) }\end{array}$ & $\mathrm{S}_{\text {Бэт }}\left(\mathrm{M}^{2} / \Gamma\right)$ & $\mathrm{V}_{\Sigma}\left(\mathrm{cm}^{3} / \Gamma\right)$ & PA ${ }^{\mathrm{a}}$ (кДж/моль) \\
\hline AM-4 & 1.28 & 20.1 & 0.07 & 1019 \\
\hline $\mathrm{AM}-4+0.06 \mathrm{M} \mathrm{HNO}_{3}$ & 0.31 & 26.7 & 0.08 & - \\
\hline $\mathrm{AM}-4+0.13 \mathrm{M} \mathrm{HNO}_{3}$ & 0.16 & 28.7 & 0.09 & - \\
\hline $\mathrm{AM}-4+0.25 \mathrm{M} \mathrm{HNO}_{3}$ & 0.02 & 30.2 & 0.1 & 797 \\
\hline
\end{tabular}

aРA - сила осно́вных центров в единицах протонного сродства.

Отмечено, что увеличение концентрации кислоты приводит к росту удельной поверхности и пористости системы. Баланс этих двух свойств катализатора важен для многих органических реакций, поскольку позволяет регулировать скорость реакции и выход продукта.

Для синтеза 1.5-бензодиазепина использовали 1.2-фенилендиамин (99.0%, Sigma-Aldrich), ацетон (Sigma-Aldrich), метанол (Acros Organics).

Максимальный выход 1.5-бензодиазепина при использовании в качестве катализатора обработанный $0.25 \mathrm{M} \mathrm{HNO}_{3}$ кислотой титаносиликат AM-4 составил 75.1 \% при 50 $\square$. Кроме того 0.25 M AM-4 хорошо подходит для использования его в циклических испытаниях. Образец может быть применен как минимум в трех циклах без изменения своих каталитических свойств.

\section{Выводы}

Титаносиликаты, безусловно, являются перспективными материалами для фотокаталитического разложения органических соединений. Поэтому изучение свойств наиболее фотоактивных образцов (IONSIVE-IE, SIV, ETS-4, SKR) целесообразно продолжить. Поскольку, в отличие от анатаза, они способны работать в видимой области спектра, что открывает возможности для получения строительных материалов и покрытий, препятствующих отложению органических загрязнений на их поверхности.

Титаносиликат AM-4 и его декатионизироаванная форма SL3 являются перспективными гетерогенными катализаторами органического синтеза ряда соединений современной медицины. Кроме того, их можно использовать многократно, что может повлиять на стоимость конечного продукта органического синтеза (лекарственного препарата).

Исследования проводились в рамках государственного задания института катализа СО РАН (проект AAAA-A17-117041710082-8), государственного задания по теме НИР Центра наноматериа- 
ловедения ФИЦ КНЦ РАН (НИОКТР АААА-А17-117020110035-5) при финансовой поддержке исследования исходных компонентов для синтеза грантом PhosAgro/UNESCO/IUPAC по программе «Зеленая химия для жизни» 2019, синтеза исходных образцов грантом РФФИ (18-29-12039).

\section{Литература}

1. González B., Trujillano R., Vicente M.A., et al. Two synthesis approaches of Fe-containing intercalated montmorillonites: Differences as acid catalysts for the synthesis of 1.5-benzodeazepine from 1.2-phenylenediamine and acetone // Appl. Clay Sci. 2017. № 146. P. 388-396.

2. IAEA Library Cataloguing in Publication Data. The Fukushima Daiichi Accident. Report by the Director General. Vienna: International Atomoc Agency. 2015. 209 p.

3. Kuznicki S.M. Large-pored crystalline titanium molecular sieve zeolites. U.S. Patent $\mathrm{N}^{\circ}$. 4853202. 1989.

4. Rempel A.A., Kozlova E.A., Gorbunova T.I., et al. Synthesis and solarlight catalytic properties of titaniacadmiumsulfidehybrid nanostructures // Catalysis Communications. 2015. V. 68. P. 61-66.

5. Timofeeva M.N., Kalashnikova G.O., Shefer K.I., et al. Effect of the acid activation on a layered titanosilicate AM-4: The fine-tuning of structural and physicochemical properties // Applied Clay Science. V. 186. 1 March. 2020. 105445. DOI: $10.1016 /$ j.clay.2020.105445.

6. Timofeeva M.N., Prikhod'ko S.A., Makarova K.O., et al. Iron-containing materials as catalysts for synthesis of 1.5-benzodiazepine from 1.2-phenylenediamine and acetone // React. Kinet., Mech. Catal. 2017. № 121. P. 689-699.

7. UOP LLC, A Honeywell Company. Efficient treatment of liquid nuclear wastes // UOP Adsorbent Solution Brochure. 2020. 4 p.

8. Воронова Г.А. Перспективы применения электровзрывного порошка диоксида титана в фотокатализе // Известия Томского политехнического университета. 2009. Т. 314. № 3. С. 41-45.

9. Курченко Ю.В., Калашникова Г.О., Шефер К.И. и др. Синтез 1.5-бензодиазепина из о-фенилендиамина и ацетона в присутствии титаносиликата $\mathrm{AM}-4$, модифицированного $\mathrm{HNO}_{3} / /$ Вестник Томского государственного университета. Химия. 2018. № 12. С. 6-15. DOI: 10.17223/24135542/12/1.

10. Николаев А.И., Кривовичев С.В. Природные минералы и их синтетические аналоги как прототипы функциональных материалов: опыт работы Центра наноматериаловедения Кольского научного центра РАН // Вестник Томского государственного университета. Химия. 2017. № 8. С. 7-20. DOI: $10.17223 / 24135542 / 8 / 1$. 